CASE REPORT

\title{
Gastric Perforation: Postmortem Diagnosis
}

\author{
Modelli MES
}

Institute of Legal Medicine of the Federal District, Brazil

*Corresponding author: Modelli MES, Institute of Legal Medicine of Federal District, Uniceub - Centro Universitário de Brasília, Brazil, Tel:+55(61)99982-3186, E-mail: manoelmodelli@gmail.com

Citation: Modelli MES (2018) Gastric Perforation: Postmortem Diagnosis. J Forensic Crime Stu 2: 101

Article history: Received: 04 January 2018, Accepted: 30 January 2018, Published: 31 January 2018

\begin{abstract}
Gastric perforation, in neonates, is a rare complication, but with high morbidity. Generally, the diagnosis is made, in vivo, in premature, low-weight children, with or without several risk factors, such as the use of mechanical ventilation, gastric tube placement, and gastrointestinal abnormalities, such as esophageal atresia, duodenal membranes, poor rotation intestinal necrotizing enterocolitis. There is no consensus as to how idiopathic forms of gastric perforation are also adventurous histologically in the musculature of the gastric wall. We presented a surveillance case, which was referred to the IML-DF for cadaveric examination, with suspicion of sudden death. During the examination, generalized peritonitis and perforation of great curvature of the stomach were identified, without other gastrointestinal activities.
\end{abstract}

Keywords: Gastric Perforation; Neonatal Sudden Death; Necrotizing Enterocolitis

\section{Introduction}

Gastric perforation is a rare and serious entity,its etiology remains obscure, often pronounced as spontaneous. The cause can be traumatic, ischemic, or spontaneous [1]. It has been discussed from several angles, including congenital musculoskeletal deficiency, high gastric acidity and ulceration, trauma, intestinal ischemia triggered by asphyxiation, increased intragastric pressure due to distal obstruction or severe aerophagia, and lack of C-Kit + cells, mast cells, or pacemaker cells (Figure 1). Of these, a common explanation is mechanical pneumatic rupture resulting from elevated intragastric pressure due to immaturity and poor neurological control in the newborn with incoordinated vomiting of a dilated stomach [2].

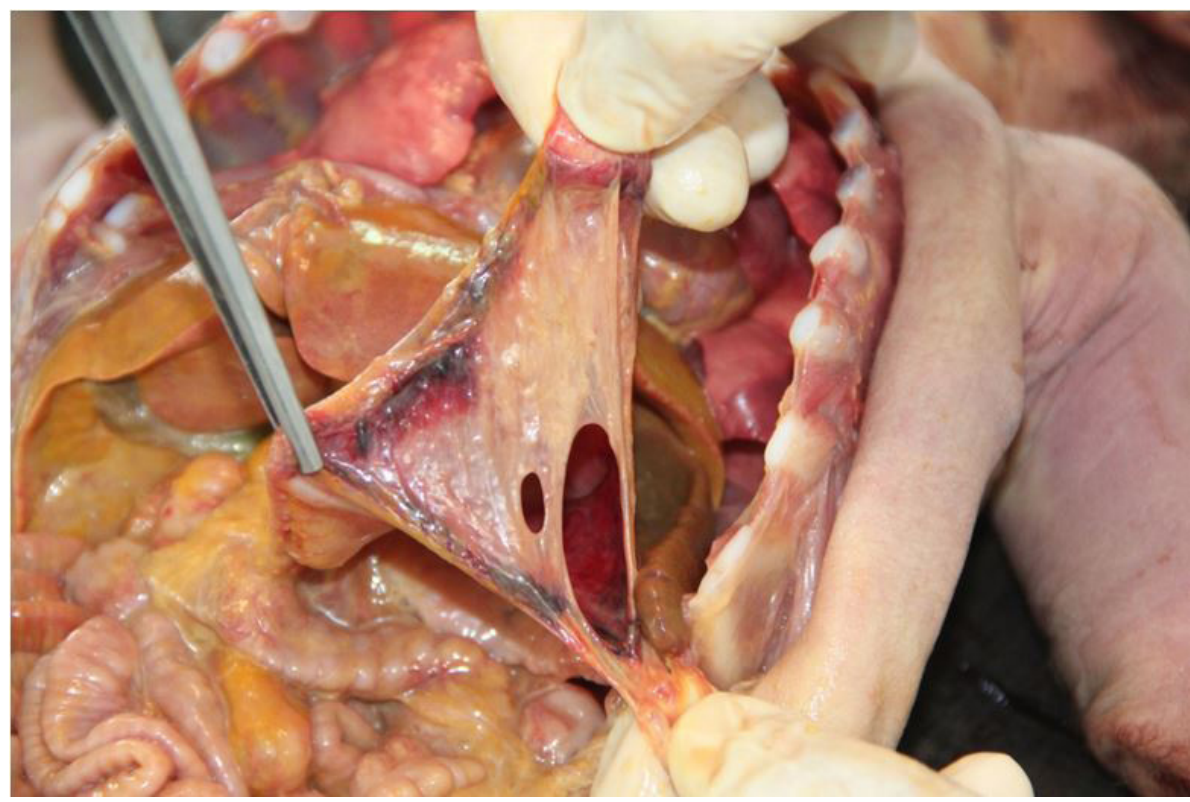

Figure 1: Aspect of gastric perforation 
Alternatively, vascular impairment, such as thrombotic vasculopathy, may be suggested. Association has been shown with acute chorioamnionitis, umbilical cord arteritis, and fetal sepsis [3]. In the series described by Shashikumar, with 19 cases reviewed, neonatal asphyxia was the most common predisposing cause (63\%) [4].

According to Houck, pneumatic rupture seems to be the most plausible explanation [5]. The mechanism is similar to Boerhaave Syndrome, with the stomach being the target. Elevated intragastric pressure may result from incoordination and immaturity of the neonate's vomiting mechanism. Gastric peristalsis is abnormal in infants, and gastric emptying is slow. Perforation occurred within the first week of life. He did a cadaver study and found that the pressure needed to break the stomach was 3.4 pounds $(7$ pounds per square). The highest incidence of rupture occurred on the third day of life.

Since 1943, Herbut defines it as a congenital anomaly, with the histopathological examination showing absence or agenesis of the smooth muscle in the greater curvature; however, Leone later showed that it was only a retraction of the muscular borders [6,7].

Wang, analyzing 15 cases in the period 2001 to 2009 , reported that the clinical manifestations of the disease were vomiting, abdominal distension, and respiratory distress [8]. Abdominal orthostatic X-ray showed free gas under diaphragm and seroperitoneum. In most cases, the stomach perforation occurred at the greatest curvature. There were thinning and defect of the stomach wall muscle and interstitial cells of Cajal reduction as seen in the microscope.

Jactel studied the role of Cajal interstitial cells, which act as gastrointestinal pacemakers and express the cKit proto-oncogene [9]. The authors have shown in 6 cases that the absence of the interstitial Cajal cells in the stomach musculature may be implicated in the development of noniatrogenic gastric perforation (Figure 2).

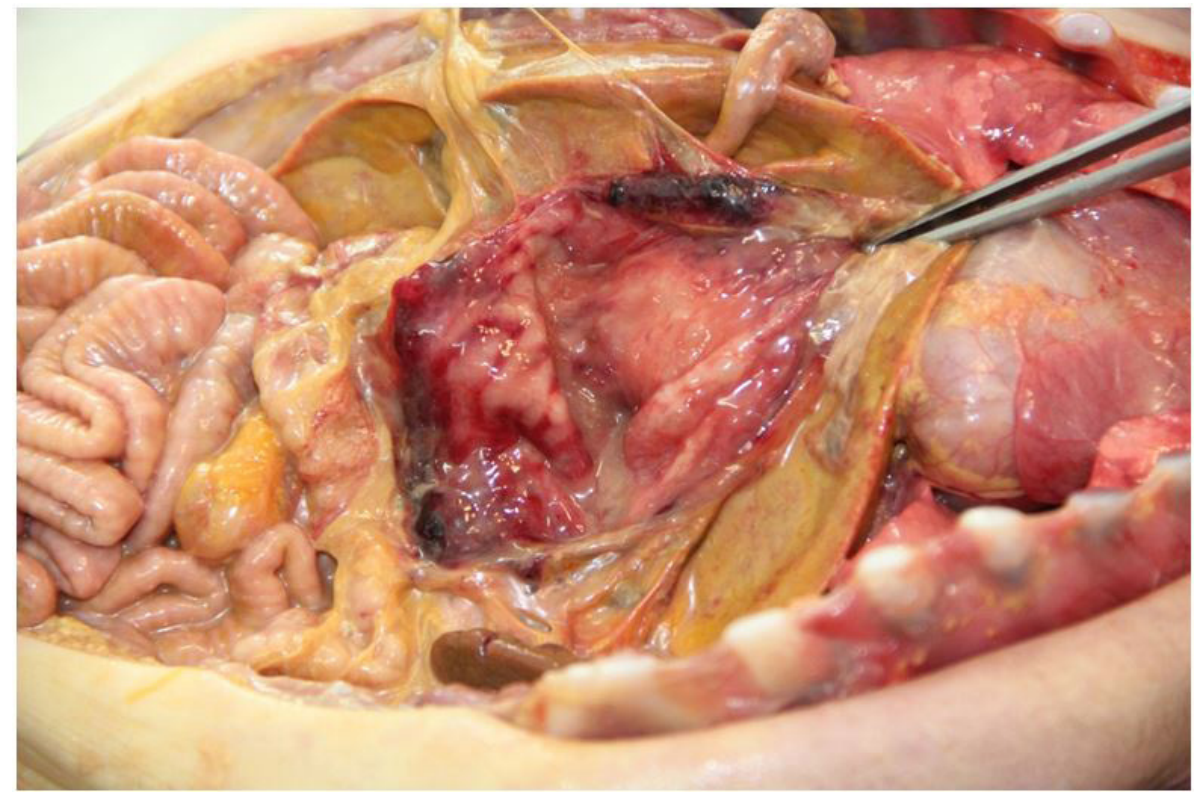

Figure 2: Aspect of the inner part of the stomach

\section{Case History}

It is a neonate of 4 days of life, who died at home, with no history of malformations or use of medications. Newborn, full term, normal delivery, with Apgar 9-10 and discharged the next day.

\section{Autopsy Findings}

The cadaveric examination revealed a newborn male, weighing $3400 \mathrm{gm}$, measuring $52 \mathrm{~cm}$ in total length, $34.5 \mathrm{~cm}$ in cephalic perimeter, $81 \mathrm{~mm}$ in feet length. The umbilical cord stump is parched and exhibits elastic bandage, measuring $3.5 \mathrm{~cm}$. Acute nodular cyanosis and subcutaneous emphysema in the anterior wall of the abdomen were observed. It presented distension of the scrotal sac, translucent to the illumination, suggesting the diagnosis of hydrocele. Scalp and brain were without changes. The thoracic cavity was open, there was no edema, and the lungs were inflated, with no macroscopic changes. Heart was without abnormalities. The abdominal cavity presented purulent ascites, with some fibrin lumps, with a volume of approximately $250 \mathrm{ml}$, compatible with generalized peritonitis. The intestinal loops were normal, with no signs of necrosis. The stomach presented great perforation along the great curvature; measuring 4 X $6 \mathrm{~cm}$, irregular, incomplete in some stretches, which persist with the serosa overlying parts in which the muscular layer appears to be ruptured. There are some small bruises along the edge of the puncture. Other structures without changes.

Histopathological examination revealed autolyzed mucosa in some areas and preserved in others, with moderate atrophy of the same and presence of focal, complete intestinal metaplasia. Intense submucosal edema, muscular with thin and almost absent areas, in addition to dense mixed, infiltrate with serous edema (Figure 3). The final diagnosis was agenesis of the muscular layer of the stomach (Figure 4). 


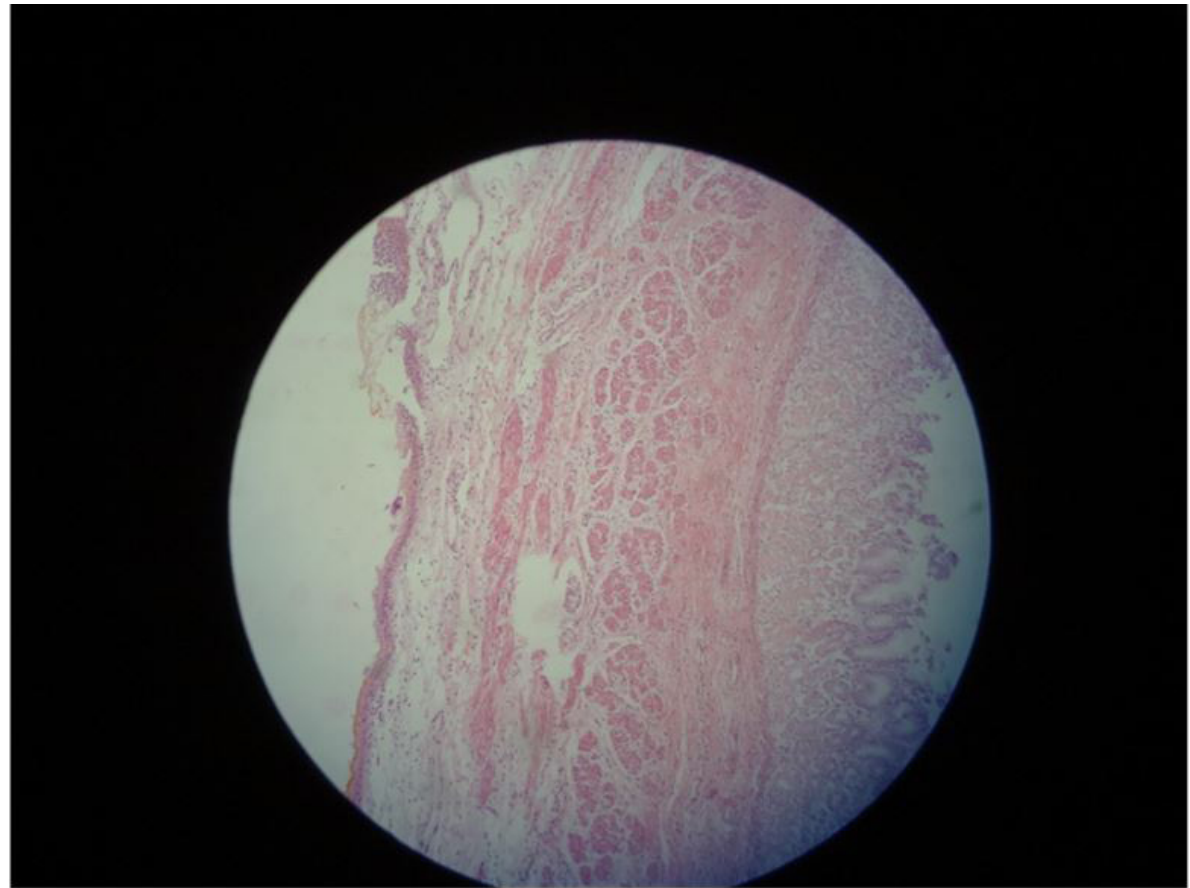

Figure 3: Mucosa autolysed in areas and preserved in others, noting its moderate atrophy and presence of focal, complete intestinal metaplasia. Intense submucosal edema. Muscular with thin and almost absent areas, in addition to dense mixed infiltrate with serous edema

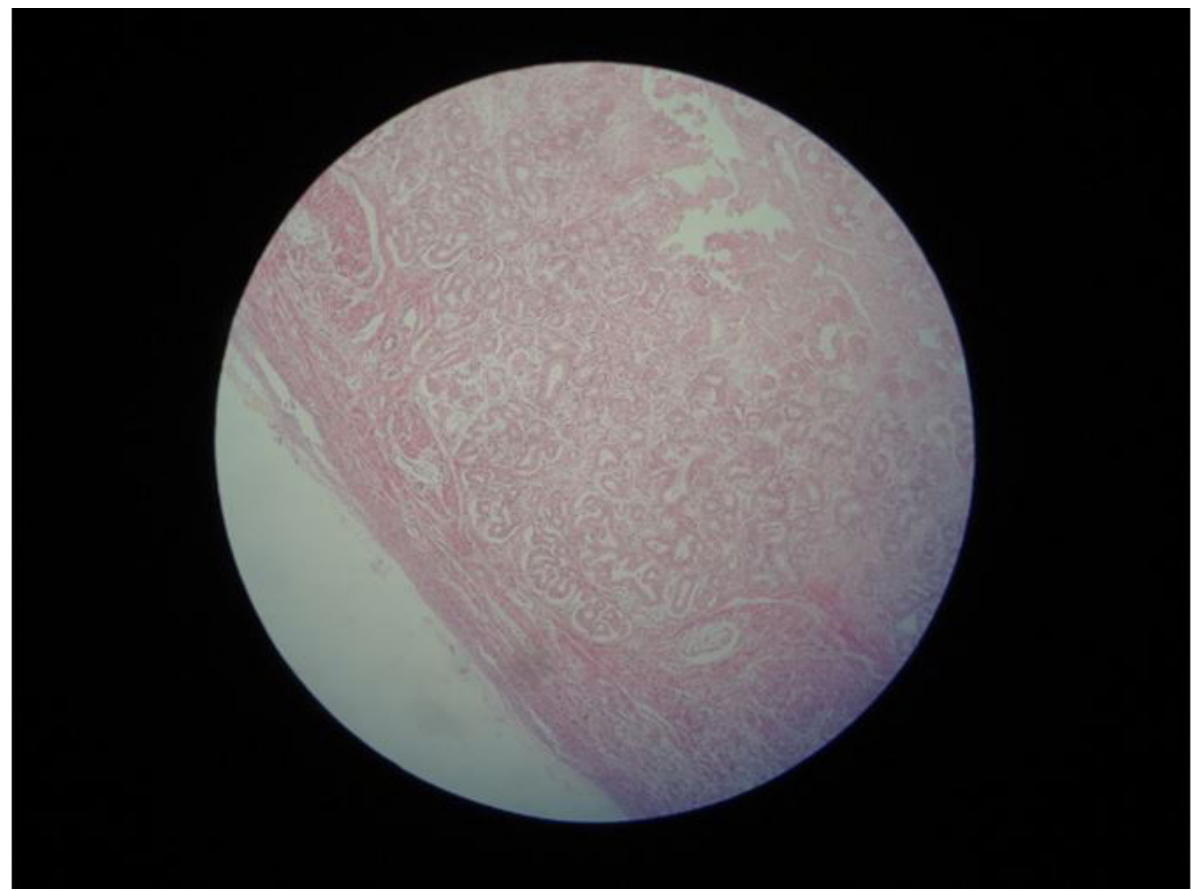

Figure 4: Muscular self with thinned and almost absent areas

\section{Discussion}

In the literature, we identified several small series of cases with gastric perforation, seen and diagnosed in children, still alive. Because it is a rare and high-mortality pathology, this was the first case seen at our Institute of Legal Medicine, whose diagnosis was made only after death. It was considered as a sudden death, without time for medical care. It is noteworthy that it is a full-term child of good weight, unlike most children who are affected by this pathology. Lee reviewed premature infants with perforations of the gastrointestinal tract, comparing gastric perforation with other sites [10]. He found five patients with gastric perforation and 11 with intestinal perforation.

Our case did not have risk factors, such as those already reported: prematurity, respiratory distress, necrotizing enterocolitis, ventilatory assistance, and so on. Duran, in his series, found perforation in the small curvature in 3 patients and in the great curvature in 2 patients, with a $60 \%$ mortality rate and suggests that infants with predisposing factors should be monitored [11]. 
Joshi reported a rare association, Carmi's syndrome, an association between epidermolysis bullosa and congenital pyloric atresia [12]. The 32-week premature infant was born with 1,200 gm and was seen on the third day with abdominal distension, erythematous skin, and an X-ray confirmed the presence of pneumoperitoneum. The laparotomy evidenced the presence of great gastric perforation along the great curvature and pyloric diaphragm

Gupta draws attention to the prevalence of premature and low birth weight, but it can also occur in term children, as is our case [13]. Dickens reported the incidence of neonatal gastric perforation as 34/1000 live births, being more frequent in men (4X), aged between the $4^{\text {th }}$ and $7^{\text {th }}$ day [14]. Byun reported 9 patients with gastric perforation and draws attention to the associated abnormalities [15]. Among the 9 patients, 3 were preterm and 5 had associated anomalies, including diaphragmatic eventration (2), diaphragmatic hernia, atresia of the esophagus with fistula and antral diaphragm. Gastric perforation occurs in $7 \%$ of gastrointestinal perforations in neonates and has the worst prognosis. Male sex, metabolic acidosis, premature birth, and low birth weight are associated with the worst prognosis. Ghribi reports 8 patients, of which 5 had associated abnormalities.

\section{Conclusion}

To conclude, because Herbut suggested the congenital absence of muscle structures as a cause of gastric perforation, multiple theories have been proposed: high gastric acidity and ulcer, abdominal trauma, ischemia, vascular shunting, absence of intestinal pacemaker cells, absence of C-Kit mast cells, spontaneous perforation, mechanical rupture, immaturity of the mechanism of vomiting, use of nasogastric probes, associated anomalies, and so on [7].

In our case, it was a full-term newborn, good weight, with no predisposing condition or risk factor that died at his residence on the third day of life, and the diagnosis was given only in the cadaveric examination.

\section{References}

1. Abdullahi LB, Mohammad AM, Anyanwu LJC, Farinyaro AU (2015) Two cases of neonatal Gastric Perforation. J Neonatal Surg 4: 34

2. Terui K, Iwai J, Yamada S, Takeonouchi A, Nakata M, et al. (2012) Etiology of neonatal gastric perforation: a review of 20 years. Pediatr Surg Int 28: 9-14

3. Mahgoub L, Lilic N, Evans M, Joynt C (2014) Stomach infarction in an ex-premature infant. BMJ Case Rep pii: bcr2013202814

4. Shashikumar VL, Bassuk A, Pilling GP, Cresson SL (1975) Spontaneous gastric rupture in the newborn: a clinical review of nineteen cases. Ann Surg 182: 22-6

5. Houck WS, Griffin JA (1981) Spontaneous linear tears of the stomach in the newborn infant. Ann Surg 193: 763-8

6. Herbut PA (1943) Congenital defect in musculature of stomach with rupture in newborn Infant. Arch Pathol 36: 91

7. Leone RJ, Krasna IH (2000) 'Spontaneous' Neonatal Gastric Perforation: Is It Really Spontaneous? J Pediatr Surg 35: 1066-9

8. Wang ZQ, Xie LW, Wu HF (2010) Clinicopathological characteristics and potential etiologies of neonatal spontaneous gastric perforation. Zhonghua Er Ke Za Zhi 48: 779-82

9. Jactel SN, Abramowsky CR, Schniederjan M, Durham MM, Ricketts RR et al. (2013) Noniatrogenic Neonatal Gastric Perforation: The Role of Intersticial Cells of Cajal. Fetal Pediatr Pathol 32: 422-8

10. Lee DK, Shim SY, Cho SJ, Park EA, Lee SW (2015) Comparison of gastric and other bowel perforations in preterm infants: a review of 20 years' experience in a single institution. Korean J Pediatr 58: 288-93

11. Duran R, Inan M, Vatansever U, Aladag N, Acunas B (2007) Etiology of neonatal gastric perforations: review of 10 years' experience. Pediatr Int 49: 626-30

12. Joshi M, Krishnan L, Kuruvila S (2012) Large gastric perforation in Carmi Syndrome: A morbid complication in a Rare association. J Neonatal Surg 1:57

13. Gupta G, Kumar S, Gupta S, Golhar, Deshpande S (2014) Neonatal Gastric Perforations: Are The Really Spontaneous? Indian J Surg 76: 319-20

14. St-Vil D, LeBouthillier G, Luks FI, Bensoussan AL, Blanchard H, et al. (1992) Neonatal gastrointestinal perforation. J Pediatr Surg 27:1340-2

15. Byun J, Kim HY, Noh SY, Kim SH, Jung SE, et al. (2014) Neonatal gastric perforation: A single center experience. World J Gastrointest Surg 6: 151-5 